\title{
The effects of discrete contextual variables on «bullying» in the schoolyard
}

\author{
Teodoro Hernández de Frutos \\ Esther Casares García \\ Universidad Pública de Navarra. Departamento de Sociología \\ theo@unavarra.es \\ casares@unavarra.es
}

Received: 22-05-2008

Accepted: 15-01-2009

\begin{abstract}
In spite of the abundance of scientific literature that exists on bullying in schools, few studies have focused on the effects, both separate and combined, caused by contextual structural variables, such as geographical space, the municipal district, family, school, gender, male hegemonic culture, and exposure to the mass media. This article reviews to the present state of knowledge on the effects of these factors and provides empirical evidence of their influence on students aged between 12 and 16 in ESO (Obligatory Secondary Education) in Navarra.
\end{abstract}

Key words: victimization, neighbourhood, family, school, gender, age, mass media.

Resumen. Los efectos de las variables contextuales discretas en el bullying escolar

A pesar de la abundante literatura científica que existe sobre el acoso escolar, pocos estudios han incidido sobre los efectos, tanto separados como combinados, causados por variables contextuales discretas, tales como el espacio geográfico, el distrito municipal, la familia, la escuela, el género, la cultura hegemónica machista y la exposición a los medios de comunicación masivos. El artículo analiza el estado actual de conocimiento de la incidencia de estos factores y añade evidencia empírica de su influencia en estudiantes de educación secundaria obligatoria (ESO) con edades comprendidas entre los doce y los dieciséis años en Navarra.

Palabras clave: victimización, distrito municipal, familia, escuela, género, edad, medios de comunicación de masas.

\begin{aligned} & \multicolumn{2}{c}{ Sumario } \\ & Introduction $\begin{array}{l}\text { Cultural varaibles } \\ \text { (hegemonic sexism scale) } \\ \text { Urban ecological variables }\end{array} \\ &$ Family variables Methodology \\ & School-related varaibles Results \\ & Age and gender variables Conclusions \\ & mass communication media Bibliography \\ & variables \end{aligned}




\section{Introduction}

Within the catalogue of possible violent acts, which may range from the most innocuous to the cruellest, special emphasis must be placed upon bullying, an English term which refers to a large and anonymous group of persons dedicated to the harassment, persecution and physical aggression directed at an individual, or to someone who torments, tortures or disturbs another, which in the school environment means that a pupil is subjected, repeatedly and constantly over time, to punishment by a peer or peers (Generalitat, 2005; Dempsey et al., 2006). One of the first authors to apply this concept was Olweus (1998), who characterized a specific behaviour of pupils in Scandinavian countries how a negative action when someone intentionally harms, injures or disturbs another by physical contact; may be committed verbally, for example by threats or ridicule, making fun or calling names. Whoever hits, pushes, kicks, pinches or obstructs another commits a negative action. It is also possible to perform negative actions without using words and without physical contact, for example by making faces, obscene gestures, deliberately excluding someone from a group, or refusing to fulfil the wishes of another person. Given that there exists some difficulty in obtaining a single definition of the term, which does not in fact exist in some countries, a type of international consensus has been reached to define it as a concept which includes various key elements such as: $a$ ) physical, verbal or psychological attacks or intimidation, intended to cause fear, pain or harm to the victim; $b$ ) an abuse of power in an asymmetrical power relationship; $c$ ) the absence of provocation on the part of the victim, and $d$ ) repeated incidents among the same children or youths over a prolonged and sustained period of time (Swain, 1998; Farrington, 1993; Rigby, 1996). Bullying is a complex phenomenon; no single cause can explain why some children bully others or are victimized; instead it is possible to identify so called risk factors that, if present, can increase the risk of becoming a bully (or a victim). On the other hand, protective factors are also important to look at because they can mitigate the negative effects of risk factors and therefore reduce the chance of occurrence of misbehaviors (Baldry and Farrington, 2005). Riske and protective factors can be related to socio-ecological variables how social class, family, school, age-gender, or culture.

\section{Urban ecological variables}

The initial formulation of thesis emanated from the Chicago School, which argued that the development and segmentation of the city explains violent acts (Carter, 1994; Fainstein and Campbell, 1996). These occur due to the effects of the "concentric areas", whose theory states that the urban population spreads out from its central area, forming a series of concentric rings or areas: the nucleus is formed by the business centre, surrounded by a transitional area in which the oldest dwellings are converted into offices and occupied by small businesses, or subdivided to make smaller dwellings. Such areas attract immigrants 
and are characterized by the existence of deprived neighbourhoods, in which socially unstable groups outnumber well-established families; furthermore, they are surrounded in turn by working-class residential districts, which include some of the city's oldest dwellings, although in such districts social groups are stable and mainly comprised of working-class families. Even further from the centre are to be found newer and more spacious dwellings, whose occupants belong to the bourgeoisie. Finally, outside the continuously built-up part, is the area in which live those who commute daily to the city and where a considerable part of its resident population have their workplaces; the boundary of this area is established at approximately one hour's journey from the city centre.

This simple model, dating from the early Xx century and fairly convincing in general terms, is logically unable to explain some of the most important questions regarding the expansion of more modern cities, and thus its detractors have criticised the development/theory of concentric rings to explain the evolution of the city, believing this to be anachronistic and of limited relevance to the reality of cities today. One such criticism is the sector theory developed by Hoyt (1939), which maintains that several zones of urban land use tend to be distributed along the principal transport routes, forming «slices of pie»; it is the location and expansion of the most desirable residential areas which structure urban space, on the basis of the attraction exerted upon them by the central administrative and business district, the prestige of the residential areas for the prosperous and managerial classes, ease of access due to means of transport and the environmental quality of each setting. This means that the internal differentiation of the city depends upon the location and growth of residential areas towards the periphery, in line with the tendency to locate upper-class areas in zones at some distance from the centre. Another explanation is provided by Harris and Ullman (1945); their multiple nuclei model considers that within the city there does not exist a single nucleus or centre, but instead that cities evolve through a series of separate centres called nuclei; each new neighbourhood incorporates its own nucleus, and thus numerous centres are constructed and expand in relative isolation. From these centres functions and spatial dispositions are radiated, to finally produce a multinuclear or polynuclear city, in terms of its spatial structure.

However, urban development is not an autonomous process, but instead is related to the processes of political and economic change taking place in the city, which is a reflection of the social tensions occurring within it. Thus, whether as cause or effect, class and status conflicts are enacted in the metropolis, since the middle and upper classes, worried by the deterioration and inconvenience of urban centres - the "neighbourhood life cycle» (Schwirian, 1993) move out to better areas which are only found on the periphery, leaving the most impoverished sectors to lower social strata. The permanent influx of the poor causes such areas to become highly vulnerable. Furthermore, the productive system of the city generates numerous low-skilled or unskilled jobs, which are filled by continuous waves of recently arrived immigrants and which are located, in accordance with the law of business attraction, in such areas, 
which suffer the disadvantages of abandoned zones. However, as time passes, or as one generation gives way to another, if its members are capable of abandoning their residential and working backgrounds, of adjusting to city life, of assimilating institutions, of climbing the socioeconomic ladder and moving to more desirable areas, their place will be systematically taken by other immigrants or new arrivals in search of opportunities, and thus the city becomes a relatively large, dense and permanent settlement, comprised of zones inhabited by individuals of a homogenous social, economic and cultural level, in which high population density produces interpersonal contact, but in which social relationships tend to be distant and segregated, producing superficial membership of different groups and, similarly, interpersonal relationships which produce neither strong loyalties and commitments, nor permanent ties of mutual/self-help in difficult times.

Another important effect of urban pressure is related to the consequences of internal urban development for the lifestyles and social cohesion of neighbourhoods. According to Wirth (1938) and his theory of «environmental conditioning", or the social experience of urban space, the population of a city has three basic characteristics: density (due to being overpopulated), heterogeneity (great differences between people) and anonymity (of social relationships), which explain how the impersonal nature of urban life causes serious social problems to proliferate. In other words, both the unbalancing nature of urban space and violent behaviour are in fact pathological responses to urban surroundings; it is no coincidence that the majority of violent acts occur in certain city districts and in specific areas which display these characteristics, normally associated with the deprived central areas, the nucleus and the peripheral zones affected by slums, sub-standard housing and inadequate urban development. According to Hall (1965), the size of cities and their rapid growth produces problems of congestion or "macrocephaly» i. e. the accumulation of persons, constructions and functions within relatively small spaces, with the consequent negative effect upon the lives of those who reside in them, in the case of the major, densely populated cities. As a result, in the last two decades numerous urban analysts (Wilson, 1993, 1987; Clark, 1968; Jencks and Peterson, 1991) have begun to talk of a new dimension of the urban crisis i. e. a large sub-population of low-income families and of individuals display behaviour which is in sharp contrast to that of the population as a whole, as shown by the dramatic increase in the 1970s of unemployment, teenage pregnancy, children born out of wedlock, female heads of household, dependence upon charity, severe delinquency, low aspirations, poor education, family instability, lawlessness, unemployment, crime, drug addiction, alcoholism, frequent illnesses and premature death.

The most discerning study belonging to this school and applied to the question of violence was that performed by Shaw and Mckay (1969) into juvenile delinquency in Chicago, which made use of the contributions to human ecology reaching the following conclusions: $a$ ) the urban districts with the highest crime rates were situated within or nearby those areas in which major 
industrial or business activity was concentrated; $b$ ) the highest rates of juvenile problems were concentrated in the geographical areas with the lowest economic level, with a higher percentage of families existing on unemployment benefit and with greater problems of alcoholism. Although their conclusion was not that poverty was directly related to violence, they were able to show that in such areas more acts of violence occurred than in others, and $c$ ) the areas with the highest crime rates coincided with districts comprised of immigrants, and thus a racial and ethnic model of violence was established.

The above mentioned study gave rise to what has been called «situational analysis», which emphasises the regularities which exist between the behaviour of individuals and their areas of residence; it is based on the idea that just as people learn how, through socialization, to respect the norms of their society, they must also learn how to distance themselves from those norms; in other words, violence is a product of socialization. As a variation of this argument, it may be stated that the values produced by socialization do not depend solely upon geographical area, but also upon membership of different collectives. The research undertaken by Shaw and Mckay in the city of Chicago tested a new clinical theory; this demonstrated that if diseases are transmitted by contagion, the same may occur with specific undesirable social habits i. e. people who live in neighbourhoods subject to robberies, violence, crime and norms different to those of society as a whole are infected by such norms and values. Consequently, the high rates of violence in certain neighbourhoods will persist even when the initial inhabitants move out of the district; this would explain the fact that new residents adopt deviant forms of behaviour, form juvenile groups of playmates and subsequently teenage gangs, as the result of a clear component of cultural transmission.

The deficiencies of the neighbourhood and the influence which this circumstance may have upon the antisocial behaviour of youths has been well documented by Wilson (1987), who associates the effect of excessively early and immature first marriages with the corresponding age at which the first child is produced. This has consequently been characterised by various explanatory models as the epidemiological or contact model, which emphasises peer group influences, the collective socialization model which underlines the positive impact of the action of adults, or the institutional model which focuses on the importance of influential figures outside the family, such as teachers, police officers, etc. As Wilson states, if the neighbourhood is so important, this is because the social class composition of its inhabitants may reduce certain undesirable effects of the ghettos, such as high rates of unemployment, crime and violence. The presence of working-class or middle-class residents will have a muffling effect, since their behaviour and daily presence act as a brake upon the deterioration of neighbourhood relationships caused by the most disadvantaged.

In summary, a considerable body of literature demonstrates that the indices of violence are substantially higher in large than in small cities and rural areas. Although authors such as Rutter and Giller (1988) argue that these data normally refer to the place where crimes were committed, instead of the place 
where violent individuals live, self-report studies (such as those of victims) have confirmed the reality of the difference between urban and rural areas with regard to both the number of crimes and the proportion of individuals with conduct disorders (Rutter, 1979; Clinard, 1968; Lavik, 1977).

The effect of specific districts or geographical areas upon rates of violence has been corroborated by, among others, by Garrido et al. (1999) for the city of Barcelona, where the study of concentric areas demonstrated the association between juvenile delinquency/crime and low economic level $(r=-.46)$. For example, the district of Ciutat Vella, with an average dwelling size of 68 square metres, displayed a rate of 45 juvenile delinquents for each 1,000 youths resident in the area (over a period of 3 years), while at the opposite extreme, the district of Sarriá-Sant Gervasi, in which the average dwelling size is 120 square metres, has a crime juvenile delinquency rate of only 2.3.

\section{Family variables}

As recent various studies have shown, the family is a social institution of vital importance for the understanding of the emergence of violence in relationships at school (Ahmed and Braithwaite, 2004; Baldry and Farrington, 2005). The family transmits norms and values, develops the abilities necessary to confront new and conflictive situations, teaches the blind behaviour of how to behave when the parents are absent, enables children to control their impulses, rewards and punishes positive and negative reactions and establishes what is socially reprehensible or acceptable i. e. it innately regulates basic conduct in life and with regard to others. The family socialization of children is therefore a basic factor in the explanation of their behaviour at school.

There exist three styles of family upbringing, depending on the type of interaction established within it and its socioeconomic level: The first of these is the contractual style, distinguished by the importance the parents place upon self-regulation and child autonomy, which in practice means little insistence upon obligation, the control of coercion and a correlative emphasis upon encouragement, stimulation and motivation. The second is the statutory style, which places great importance upon obedience and discipline and less emphasis upon self-regulation and children's sensitivity; it is concerned more with control than motivation or the relationship, and the distances between parents and children are considerable. The third style is the maternal style, characterised by its emphasis upon accommodation (obedience and conformity) rather than autonomy and self-discipline; its techniques are based more upon control than upon motivation or the relationship, although there exists close communication between parents and children, who undertake many activities together (Kellerhals and Montandon, 1991).

Although, broadly speaking, a family style may be established with regard to the socialization of its children, the fact that one of the family members displays aggressive conduct towards the others has meant that the analysis of the effects of the family has taken into account any type of detail, however irrele- 
vant it may seem. This fact may indicate that the family is giving differential treatment to each of its children, according to his position, structure and individual characteristics. Favouritism i. e. parents' preference for one of their children, which is explicit in the case of indulging younger children compared to their older siblings, or even the predilection for one child rather than another, which provokes the jealousy of the others, has been one of the factors most commonly taken into consideration when measuring the differences in conflicts and deviant behaviour occurring in families comprised of three children, compared to those comprised of two or four (Rutter and Giller, 1983).

The basic difficulties represented by details which are so difficult to test have meant that two basic research lines into family relationships have become consolidated. The first of these has concentrated on structural effects, in which important variables include household size, the number of siblings and the position they occupy in the family hierarchy, the absence of one of the spouses due to desertion or death, the physical or mental illnesses suffered by a members of the family, the unemployment of the parents, the age of the parents, the age at which they were married, the age at which they had their first child, sharing a dwelling with other relatives and living with non-biological fathers and mothers. All these factors imply that changes in one or more of these variables produce a change in relationships in general; for example, when the number of children is large, this automatically produces changes in behavioural control and the method employed to implement rules and emotional behaviour.

Specifically, and has been demonstrated, family size can be positively correlated with a greater tendency towards deviant behaviour. Similarly, the distance between siblings generates differences in family behaviour, given that the greater the gap between births, the better is the climate for the family members as a whole, since the parents may dedicate more time to each child, less dependence exists, the disciplinary style can be more relaxed and collaboration between siblings can be improved, as moments of tension produced by competition for the same resources do not exist). The second research line views interactional effects as more important. Among these should be emphasised the emotional climate, the communication with the mother, the effects of the example-model of the parents' behaviour, educational practices, the lack of supervision, parental cruelty, the lack of communication, strict or weak discipline, parental rejection, hostility and stress. Longitudinal studies have demonstrated that interactional variables directly affect antisocial behaviour, while structural variables have more indirect affects, via other variables such as family communication (Wagner et al., 1983; West and Farrington, 1982).

The lack of parental control, overly strict or erratic discipline, the rejection of the children, a lack of involvement with them and poor marital relationships are the five most important variables for predicting violence, in both adolescent and adulthood (Loeber and Stouthamer, 1987). It appears that family situations in which there exist frequent and prolonged arguments, the temporary separation of the parents due to disputes, the expression of hostility and negative feelings between family members and attitudes of disdain, shout- 
ing and punishment directed at the children are particularly explanatory. Equally, the lack of communication between parents and children appears to affect the violent behaviour of the latter, as do situations such as the absence of recreational activities undertaken in common, the lack of intimate communication, the absence of emotional identification with the parents and the absence of paternal affection and warmth; these lead children to reject the family surroundings and to take refuge in gangs of friends. Of great importance is the lack of reasonable supervision and control of the children outside of school, of what they do and who their friends are i. e. an excessive permissiveness shown by not asking the children where they are going, at what time they will return, allowing them to wander the streets, not knowing exactly where they are, overly lax timetables, not seeing them all day long and "parking» them at school.

Such attitudes may lead to deviant juvenile behaviour, especially at the onset of adolescence, when children spend less time under their parents or another adult's supervision and more time with their peers. It has been demonstrated that the most undesirable activities, including fighting amongst pupils and antisocial or delinquent behaviour (often derived from friendship with deviant acquaintances), usually occurs when parents do not know what their children are doing (Hetherington, 1993; Kim et al., 1999). The four fundamental factors which produce this tendency are: $a$ ) the absence of family rules (mealtimes are not fixed, domestic tasks are not distributed, the children do not know what is permitted or forbidden); $b$ ) the lack of parental control over their children's behaviour (the parents do not know what their children are doing or what they think, and believe that their children do not engage in deviant behaviour and do not control it); $c$ ) the absence of emotional support (the parents scold and shout but do not reward their children sufficiently and do not encourage prosocial instead of antisocial activities), and $d$ ) continual tensions and disputes between parents and children which do not resolve anything (Patterson et al., 1992).

The effects of the emotional relationship between the parents are particularly intense; situations of pre- and post- divorce/separation have enormous repercussions upon the children at all levels: emotional, economic, personality, status, etc. From among the extensive literature which exists with regard to this phenomenon, which affects more and more adolescents each day, the sources which demonstrate the harm caused to children even 11 years before their parents' separation are particularly revealing (Shaw, 1999). As Olweus (1998) argues, the educational environment factors which influence violent conduct are closely related to the relationships maintained by the adults in the family; the frequency of conflicts, disagreements or arguments between the parents, whether or not these end in divorce, cause their children to feel insecure. Thus, parents should refrain from involving their children as allies in intra-family arguments, since it has been demonstrated that if parents settle their differences in private rather than in front of the children, the negative effects upon the latter are fewer. According to Popenoe (1996), a strong rela- 
tionship exists between the method used to resolve family conducts and child behaviour; for example, when a traumatic parental separation occurs or a predivorce situation exists, an increase in tension can be detected, which may affect the level of violence of the children, as a result of the degree of frustration to which they are subjected.

Bullies can be distinguished by their home environment, they parents are more likely to endorse an authoritarian parenting style (Ahmed and Braithwaite, 2004). Poor parenting means that parents do not support their children and use an authoritarian rather that authoritative style (Rigby, 1996, 265). When children are frequently punished, physically or psychologically, by either parent for no apparent reason, they develop less protection against violence in general, because they internalize low self-esteem, lack of security when confronting problems, and lose hope that their problems can be solved, which makes them likely to reproduce violence with their peers or likely not to know how to react against it, becoming either bullies or victims of bullying. For this reason, importance is given to family-related factors of protection or risk together with school-related factors and to the fact $\mathrm{b}$ that both types are related to the model of authority found therein (Baldry and Farrington, 2005).

\section{School-related variables}

Although the school is a factor which may be determined by geographical or residential area, the different types of school (private, public, religious) and their different characteristics e. g. close or loose supervision in the classroom/playground/dining room, the effect of discipline, selective entry to the school (i. e. the admission or rejection of violent or troublesome pupils), aggressive architectural spaces, management type and style, proximity to places with a lot of noise, pollution, etc., may determine whether pupils are relaxed or stressed. Various studies have found significant differences in both the indices of deviant behaviour, such as truancy, and in violent and disorderly conduct, depending on the school in question. Furthermore, the authors of such studies have suggested that the type of school may have an important influence on pupils' behaviour and thus affect the overall indices of behavioural disorders, since «in all schools pupils vary greatly in their cognitive and behavioural characteristics, but in some schools there exists the general tendency in the group of pupils as a whole to behave better or in a disorderly way. It is this tendency which appears to be moulded by the characteristics of the school» (Rutter and Giller, 1988). This influence is determined by the surroundings, since, as has been shown, school-related factors have a considerably greater effect upon the conduct of pupils in class than upon violent activities out of school. Normally, the type of admission (free or selective) has been used as a powerful predictor, given that some schools admit a higher proportion of children with problems of conduct, and thus the differences between schools with regard to the index of violence or antisocial conduct are simply a consequence of these differences in admission policies. 
Similarly, another variable (parental involvement) may be determinant in child behaviour. Parents may be active in school affairs in two different ways; at a collective level they may participate in their school council and in the elections held to elect its members. According to data from the National School Council, such participation in Spain is generally low in secondary education, further education and vocational training, and slightly higher in primary education, special education and infant education. This implies that parents only participate in the election of their representatives on school councils when their children are under 12-14 years old. Individual participation takes place by involvement in the various year-end activities organised in schools and in the supervision of the progress of their children through direct communication with their teacher. According to the INCE report (1997, p. 191) the degree of parental participation is fairly or very high $(46 \%)$ in the first stage of primary education and low (24\%) in the second stage (11-12 years old), while the degree of collaboration is fairly or very high in the first stage $(55 \%)$ and high $(40 \%)$ in the second stage (11-12 years old). These data demonstrate the existence of greater supervision by parents of what takes place at school at ages prior to adolescence.

Thus, although the school is the second most important variable for the explanation of the ethiology of violent acts, it is the principal subject of the present study as it is where children spend most of their relational time, where they are make contact with their peers and where they witness violence; thus, the study was performed in schools rather than elsewhere. Various publications have demonstrated that good progress at school and willingness to learn have been factors which restrain violence, while academic failure, laziness and imposition have been factors which explain aggressiveness. Within the school, the relationships maintained among its components constitute what is known as the school environment, represented by the constellation of factors developed structurally within its precincts. The attitude in general to school has been measured by the following questions: How do you feel at school? Have you been afraid to come to school? What is the principal cause of your fear? How do you get on with your schoolmates? How do you feel the teachers treat you? Table 5 shows the existence of a close relationship between the feelings produced by the school and children's ill-treatment of their schoolmates; greater dissatisfaction increases such ill-treatment. Similarly, the relationships children maintain with their schoolmates affects the degree of aggression they display towards their peers.

The next question which may influence the manifestation of episodes of bullying is the general climate of violence which adolescents perceive in their school. School satisfaction is a major aspect of children's quality of life. The level of school satisfaction is important because it affects psychological wellbeing, as well as school engagement, absentee rate, drop-out and behavioural problems (Verkuyten and Thijs, 2002). Those pupils who feel most unhappy at school are those who perceive a greater degree of abuse; those who state they are very unhappy and that they do not like school account for $26.7 \%$ of those 
who perceive that almost every day a schoolmate has abused another or others, one of whom may be himself or herself. The second part of the table confirms the contents of the first part; although the great majority of pupils declare they are not afraid to attend school, if we compare this item with the following one, it is clear that those who declare they are sometimes afraid are more likely to state that a schoolmate has ill-treated another or others more than 4 times or even almost daily.

It is possible that the principal characteristic of violence at school is that it forms part of a hidden curriculum i. e. it must be understood that the violence which takes place in schools during adolescence fulfils a function of trial and error, subordinated to the control exercised by adults, such as teachers, monitors and, in general, adults with responsibilities in the school. It is precisely the non-official nature of such violence and its prohibition which makes pupils look for the ideal space for it to enjoy complete impunity; logically, this means that violence is exercised in places outside the control of teachers, monitors and other adults. According to Siann et al. (1994) and Whitney and Smith (1993), assaults are most frequent in school playgrounds and classrooms, while Olweus (1998) maintains that the majority of assaults take place in the classroom. The places in which scenes of aggression and violence occur demonstrate that although order is maintained, there exist significant differences between boys and girls.

\section{Age and gender variables}

As has been sufficiently demonstrated, there exist differences between the violent acts performed by children of different ages and genders (Archer and Colé, 2005; Pepler et al., 2004). There appears to be little doubt that antisocial behaviour may increase from early adolescence - important formative period for aggression - until early and late youth, for both men and women; additionally, while boys develop physical and personal aggressiveness from their first years at school, girls tend to express their antisocial behaviour at later stages, above all during adolescence (McGee et al., 1992; Zoccolillo, 1993; Loeber and Stouthamer-Loeber, 1998). The consequences of adolescent aggression are often cumulative and can have lasting negative effects on subsequent developmental outcomes and relationships (Moffit et al., 2001) even are likely to continue to use power in relationship over the lifespan (Craig and Pepler, 2003) or workplace (Dilts and Harryman, 2004). During adolescence, boys tend to be more confrontational in their aggression whereas female exhibit higher levels of indirect, or relational, aggression than do males (Crick et al., 2004). Besides, if violence is measured, taking into account sibling influence, it can be observed that when the youth has a female older sibling instead of a male older sibling, his/ her level of violence is practically inexistent compared with when the older sibling is male. Thus, aggression increased more quickly for those with male older sibling (Tierney, Jewsbury and Blozis, 2007). 
The observation of the interactions produced in the school playground and even in the classroom itself demonstrated the territorial domination enjoyed by boys compared to girls; communal spaces are dominated by the recreation of the former, who play sports (particularly football), at the expense of the activities of the latter, which are reduced to a ghetto-type scenario. The practice of this sport means the occupation (depending on the school) of $75 \%$ of the playground, or even more if we take into account the risk of being hit by a football run by those persons nearby. On the other hand, according to Grugeon in The Norwich study, this imposition has permitted girls to develop more substantial activities in which creativity, imagination and socialization prevail, also the cooperative nature of the recreational activities of girls, via a complete range of games observed, which include songs, rhymes, clapping and dynamic games, by contrast, the predominant feature of boys' games is rivalry and a tendency towards conflict and confrontation which may easily degenerate into fighting, boys' games appear to lack that sociability which was such a marked characteristic of girls' games (Grugeon, 1995).

The ways in which bullying materialises may take different forms and degrees of intensity, according to Glover et al. (2000) in a study of pupils of 11 to 16 years of age; interprets bullying as the invasion of others' space and states that there are three principal types of violence: physical, verbal and attacks against possessions. The most easily remembered of these, by those who completed the questionnaire, was the first, especially if it had occurred in the current school year, although the other two forms were more deeply embedded in their memory if the aggressor continued in the same class. The difference between the physical violence committed by boys and girls, most commonly expressed in pushing, punching, tripping and kicking, is that although girls may have been aggressors at certain times, they almost never took reprisals,; furthermore, it was highly likely that they were victims at other times. Verbal violence, such as mocking and name-calling directly affected $26 \%$ of pupils, although $52 \%$ had witnessed such events; this practice was more common among boys than girls, despite teachers' statements to the contrary. Nevertheless, exclusion from the social group was a typical practice among girls, affecting $11 \%$ of them. Damage to possessions was less frequent than physical violence, although the majority of pupils stated that damage had been caused to their possessions, such as clothes, bags and books, and even that money had been demanded from them. Despite variations in the figures, the data provided by Glover and his team largely coincide with studies performed in Sweden (Olweus, 1998), the United Kingdom (Sharp and Smith, 1994) and Spain (Ortega and Mora-Merchan, 1999). The Spanish study provided the following data: insults $(3 \%)$, rumours $(12.2 \%)$, theft $(11.8 \%)$, threats $(8.4 \%)$, physical attacks $(5.7 \%)$ and isolation $(5.5 \%)$.

\section{Exposure to mass communication media variables}

The influence of mass communication media upon the violent conduct of young people has been explained by various theories and authors (Ballard $e t$ 
al., 1996; Anderson and Dill, 2000; Kuntsche, 2004); these show how frequent exposure to certain violent scenes infects the viewer, creating inoculation for their behaviour. According to Brody (1977), violent films are capable of leading to the imitation of aggressiveness in young people, particularly in very young children and in those whose development has been seriously affected by the absence of a process of normalized socialization. In turn, Stein and Friedrich (1975) have shown that violent television programmes may have a greater impact upon individuals who were already clearly aggressive and whose aggressive behaviour patterns were circumscribed to their exposure over long periods to high levels of violence. According to Kellner (1995), a substantial change has taken place in the education of adolescents; while traditionally they were educated by means of fairy tales, traditional stories and children's books, and by institutions such as the family, school and church, today media culture has replaced traditional institutions as important instruments for socialization. Young people often receive their role models and materials to shape their identity from mass media companies, which have produced a dramatic irruption of commercial rather than traditional elements. In other words, a new culture has emerged, one based on the media, pop music, television, the cinema, videos and computer games, which create new idols, aspirations and appliances/artefacts which strongly influence the beliefs and behaviour of young people today.

However, in the opinion of Steinberg and Kincheloe (2000), although it is impossible to establish statistically valid causal connections between violence in the mass media and the violent behaviour of children, from a more qualitative perspective a violent juvenile culture favours violence as the most effective method of resolving the day-to-day problems of children; this trend tends to worsen due to the fact that the pressures of competition encourage sponsors of children's television and producers of children's cinema to produce more violent products, which give rise to greater profits. The study of Zillmann and Weaver (1999) on cognitive framework showed that prolonged exposure to violent films led to hostile behaviour in unprovoked participants. The same may be said of videogames, which have displayed an increase in violence since the first games launched onto the market until those produced in the mid1990s, according to Provenzo (2000), in such games, it is necessary to immerse oneself in the virtual cosmos of the battle for survival and learn to mutilate and kill all rivals, and thus a mental predisposition towards violence is established, given that violence becomes a natural amphetamine and a legitimate right to use death to "get high" and to combat the boredom of postmodern infancy. Relationships between television viewing in childhood and adolescent and aggressive and violent behaviours in adulthood have been established as longitudinal research (Johnson et al., 2002; Huesmann et al., 2003) as metaanalyses of experimental studies revealed a highly significant association between exposure to television and aggressive or antisocial behaviour among children and adolescents (Paik and Comstock, 1994).

The results of a study carried out in eight countries investigating the relationship between television viewing and different forms of bullying are espe- 
cially relevant for this epigraph. The results point that although all different forms of bullying were associated with television viewing in bivariate analyses, only the verbal forms («calling mean names» and "spreading rumours») remained significant in multiple regression models. These relationships were observed consistently in all eight participating countries. However, the association between television viewing and physical forms of bullying such as kicking, pushing, or shoving around, varied across countries. In most weekend TV viewing cultures, frequent television viewers were prone to kick or push another student in addition to verbal forms of bullying, which was not the case in weekday viewing cultures. These results demonstrate the importance of limiting adolescents time engaged in unsupervised television watching, and the need to motivate adolescent to engage in joint family activities or organized afterschool activities (Kuntsche et al., 2006).

\section{Cultural variables (hegemonic sexism scale)}

Among the western cultural variables which are most important in the socialization of children is that called hegemonic sexism i. e. the traditional and patriarchal atavistic belief in the power and supremacy of males, based upon traditional gender roles, and in masculine strength is an acceptable method to use to get one's way. This includes the right to view control over women as legitimate, to resolve interpersonal conflicts by the use of force and to recover the status of masculine power, when this is threatened, by dominance. Such acts, according to Askew and Ross, in their book «Boys Don't Cry» represent a «dominant vision of men with which the press and other media bombard us constantly, presenting them as tough, strong, aggressive, independent, brave, sexually active, relational, intelligent, etc.» (1991, p. 14).

For Connell $(1987,1995)$, there exists a nexus between the positions of hegemonic sexist ideology and the use of violence; this nexus may take shape in the four types of masculinity based on social, cultural and institutional models of power: hegemonic, subordinate, complicit and marginal. The first of these is widely used in discussions of masculinity and refers to those forms of domination which attempt to achieve the highest status and exercise of influence and authority on the basis of patriarchy, through many cultural and institutional practices which involve the communications media; they are constructed in the public sphere with regard to women and subordinate masculinities, although this does not imply an all-encompassing process without options and without resistance. Thus, personal and social difficulties often arise from the pressures upon boys to prove their masculinity and conceal their vulnerability. The second form is diametrically opposed to the first and is rejected by the circle of masculine legitimacy, and fits within what may be termed gay masculinity, under constant pressure from the first form. The remaining two forms fit within these two.

In the opinion of Kenway and Fitzclarence (1997), the literature is replete with cases which illustrate tribal rivalries among boys at school and which 
demonstrate that they develop a distinctive style of masculinity in their wars, in which relationships of domination and subordination are established on the basis of the use of physical violence, both legitimate (through sport) and illegitimate (through harassment and bullying). This style of masculinity is founded on the belief in the importance of aggressive and violent acts performed to maintain status, reputation and resources, as a form of self-protection of masculine identity within the group. The problem is that violence has a highly symbolic value for the acquisition of masculine identity, as it is linked, especially in intermediate ages, to the achievement of positions of power and privilege. Given that the positions reached are usually unstable, their maintenance requires great insistence, which obliges boys to dedicate greater effort and attention. Moreover, considerable evidence exists to support the thesis that violence is a daily occurrence at school, that the majority of violent acts are perpetrated by boys and that they may be classified as violent expressions of certain types of masculinity. Consequently, schools may play an important role in the prevention of violence, although few advances have been made in this field. According to Subirats (1999, p. 30) «the fragility of masculinity, especially of hegemonic masculinity, is something that has been repeatedly underlined in analyses of the male gender and is understandable in view of the idea of violence, competition and triumph as the basis of the affirmation of masculine identity».

Thus, the study included a set of questions concerned with sexist attitudes, in order to measure the effects of sexist stereotypes upon the use of violence; some of these questions were based on the theories employed in different studies. For example, according to Spender (1983), Stamworth (1983) and Torres (1996), girls do not attempt to play a prominent role in the classroom, as this entails wasting resources which would hinder the achievement of better academic results. On the other hand, boys are more active and boisterous, constantly requiring the attention of the teacher, to the detriment of girls.

\section{Methodology}

The survey was based on a sample group of 603 pupils in Compulsory Secondary Education in Navarra (Spain). The final unit of the sample was a class chosen at random from among the schools selected. The questionnaire used was basically the Olweus (1993) model. The survey was performed in May, to be able to take into account the events of the school year. Both the research objectives and the adequate completion of the questionnaire were explained in detail by the research team. School representatives were not allowed to be present in the classroom while the questionnaires were being completed, to ensure anonymity No personal identification whatsoever was required.

The nominal variables were transformed into dummy variables in the case of gender ( 1 for males and 0 for females), of school type ( 1 for state schools and 0 for private) and of exposure to violence i. e. «Do you remember witnessing a violent act on TV, in the press or at school?» ( 1 for yes and 0 for not). Social class was approximated by using various neighbourhood charac- 
teristics (e. g. households below the poverty line, unemployed persons and immigrants). In addition, house prices were taken into account, and all the above were used to form three groups corresponding to low, middle and upper socioeconomic status. Family and school climate were indicated using a classic four-point scale $(1=$ very good, $4=$ very bad). The different measurements of bullying and TV watching frequency were also obtained using a 1-4 scale.

Furthermore, an attempt was made to ensure that the schools selected reflected in some way social classes and neighbourhoods, in order to test two hypotheses of residential theories: $a$ ) violence may be a cause of the social disorganization occurring in some areas of the city, as a result of the decrease in the social control exercised by neighbours and various collectives, who act as a restraint upon the performance of criminal acts. Although, in principal, this theory is aimed at measuring the influence of the immigrant population, whether national or foreign, the low level of immigration in certain ages of Navarre prevented it being tested- nevertheless, it remains valid in order to obtain a measurement of the zones, and $b$ ) the differences existing between rural and urban areas. Another theory considered to be important in/relevant to the interpretational framework of the study was that known as differential association according to which violent socialization is not produced solely on the basis of geographical area, but also on the basis of membership of specific collectives.

\section{Results}

The results of the study in Navarra (Hernández, 2000; Hernández and Casares, 2002) tend to corroborate earlier theories, since they demonstrate a higher ratio of violence in schools located in the area of centre and the surrounding area in comparison to the other three areas of South, Southeast; North, since Pamplona registers twice the percentage of witness records of violent acts. This may be the result of it being a city of 200,000 inhabitants i. e. it is more urbanized, more crowded and has larger districts than the other, much smaller towns. The general conclusion in this regard is that the greater the size of the municipality, the higher is the incidence of bullying in schools. Similarly, comparing the two most urbanized areas of Pamplona and its surroundings and South, South-east and North, the figures are also higher, and thus we are able to confirm the initial hypothesis. However, caution must be exercised on this point, since the sampling errors of the last two geographical areas do not permit a balanced comparison to be made.

Moreover, the results of the effect upon violence of the location of schools in Pamplona and its surroundings are conclusive, since schools located in the most deteriorated neighbourhoods or districts or those with the lowest socioeconomic levels display higher rates of ill-treatment of fellow pupils. Thus, 70\% of pupils in two schools, one using Castilian Spanish and the other using Basque as the teaching language, in close geographical proximity within an area which may be considered as deteriorated, have participated in bullying, 
Table 1. Descriptive statistics

\begin{tabular}{lccccc}
\hline & N & Means & Standard deviations & Mínimo & Máximo \\
\hline Gender & 603 & 0,52 & 0,500 & 0 & 1 \\
Age & 603 & 14,98 & 0,969 & 12 & 19 \\
School type & 603 & 0,54 & 0,499 & 0 & 1 \\
Climate in family & 603 & 1,35 & 0,568 & 1 & 4 \\
Climate in school & 603 & 2,00 & 0,750 & 1 & 4 \\
Victimization & 603 & 2,17 & 0,971 & 1 & 4 \\
External bullying & 603 & 1,94 & 0,864 & 1 & 4 \\
Individual bullying & 603 & 1,65 & 0,627 & 1 & 4 \\
Group bullying & 603 & 1,47 & 0,720 & 1 & 4 \\
Friends & 603 & 1,47 & 0,650 & 1 & 4 \\
Exposure to televisión & 603 & 1,85 & 0,618 & 1 & 4 \\
Esposure to Violence & 603 & 1,11 & 0,319 & 1 & 2 \\
\hline
\end{tabular}

compared to figures for other areas which range from a minimum of $23 \%$ to a maximum of $57 \%$. Table 1 shows the descriptive statistics.

Family: The majority of the sample belongs to nuclear families i. e. they live with their fathers and mothers, while $9.65 \%$ of boys and $9 \%$ of girls live either only with their mother or father. Finally, $1.3 \%$ of boys and $0.7 \%$ of girls, in cases of orphan hood or extended families, live with other relatives (grandparents, uncles, cousins, etc.). A considerable part of the sample feels happy with the family (70\% of the boys and $67.6 \%$ of the girls); $26.5 \%$ of the boys and $27.9 \%$ of the girls feel reasonably happy, $2.9 \%$ of the boys and $4.5 \%$ of the girls are neither happy nor unhappy, while $0.6 \%$ of the boys and $0 \%$ of the girls feel they are badly treated. Children who live with only their fathers or mothers are more inclined to ill-treat or bully a fellow pupil «almost every day», while those who live with other relatives are more likely to ill-treat or bully a fellow pupil «sometimes». These data demonstrate (although the sample size demands the necessary caution to be exercised) the advantages of the nuclear family with regard to violent attitudes among children i. e. if they live with their parents, it may be said that such attitudes are more benevolent. Family means that violent attitudes are less frequent than in the alternative scenarios. The association between family and violence at school is therefore corroborated. Another important question for the evaluation of the development of family relationships is when adolescents are asked to whom they report the problems of violence they observe; as has been well documented, one of the characteristics of this age is the progressive reluctance to share problems and confidences with the family, and instead to recount them to friends. The results show that $47.35 \%$ of the sample, when they observe these problems, share them firstly with their friends, $30.55 \%$ do not discuss them with anyone, $8.25 \%$ talk to their families and $2 \%$ consult their teachers. The progressive distancing from the family which occurs at this age is also confirmed.

School: Aggression may occur anywhere; that is to say, it occurs in an indeterminate rather than specific place. This is the result of the architectural design 
of the school, which has spaces where it is difficult for an adult to be present. It must therefore be concluded that harassment takes place indiscriminately in various places at the same time, but it is the classroom, as the in-depth interviews confirm, where the spark is produced; in the final analysis, it is where most time is spent, and thus it is the specific place where the majority of attacks occur. However, what may be called the final outcome of a fight or of a serious attack frequently takes place in the playground, where there usually exists less vigilance and where it is difficult for someone to intervene.

Age and gender: On the basis of the percentages supplied in our study, it may be concluded, on the one hand, that there exist clear differences in the acts of violence committed by boys, which consist more of physical contact, fighting, pushing or tripping, and those occurring among girls, which include what has been termed relational violence or exclusion, commonly expressed as "laughing at them», «ignoring them» or "talking behind their backs». Secondly, it may be underlined that the most repetitive forms of interfering with others comprises the cluster of insults, making fun, name-calling and physical abuse, with little variation between males and females and between public and private schools. Demanding money is the least common practice, although it is probably the most serious and disturbing form of aggression, since it could lead to criminal acts. Thirdly, when an analysis is performed by age, there can be observed a qualitative leap between the ages of 13 and $14 \mathrm{i}$. e. the transition from the first to the second stage of compulsory secondary education.

Media communication: The frequency with which television is viewed by the sample displays a clear difference between boys and girls; $55.6 \%$ of boys and $63.8 \%$ of girls watch TV «between 2 and 3 hours a day», $26.2 \%$ of boys and $24.5 \%$ of girls watch "less than 1 hour a day», $11.5 \%$ of boys and $7.9 \%$ of girls watch "more than 4 hours a day", $3.8 \%$ of boys and $2.4 \%$ of girls watch "on the weekends» and $1.3 \%$ of boys and $0.7 \%$ of girls «never or almost never» watch TV. There also exists a clear difference with regard to the programmes watched; $33.5 \%$ of boys and $60 \%$ of girls watch "children's series», $31 \%$ of boys and $8.7 \%$ of girls watch "sport», $26 \%$ of boys and $23.8 \%$ of girls watch «films", while $9.3 \%$ of boys and $7.4 \%$ of girls watch "other programmes». There exists a clear relationship between the number of viewing hours and accosting or ill-treating a fellow pupil, since as viewing time increases so does the frequency of the second variable. Moreover, "going out with my boyfriend/girlfriend" or "going to bars or discos» produces an increase in the practice of violent acts; this suggests that inappropriate or precocious maturity, expressed in certain precocious acts (going out with a girlfriend/boyfriend or going to bars and discos) is correlated with the process of deviation which violence represents. The exposure to acts of violence against women in the communications media is a daily occurrence for the pupils consulted; the majority of them $(85.9 \%$ of boys and $90.7 \%$ of girls) remembered seeing a harmful act against women. Many of these acts were reflected in an open question which requested pupils to mention three scenes of violence against women 
Table 2. Correlations matrix

\begin{tabular}{|c|c|c|c|c|c|c|c|c|c|c|c|c|c|}
\hline & Clase & Gen & Age & Schoo & Clim & Clim & Victi & Exter & Indivi & Group & Friend & Exptv & Expv \\
\hline Clase & 1 & & & & & & & & & & & & \\
\hline Gender &, 024 & 1 & & & & & & & & & & & \\
\hline Age & $-214^{* *}$ &, $125^{* *}$ & 1 & & & & & & & & & & \\
\hline School &,- 049 &,$- 089^{*}$ &, 033 & 1 & & & & & & & & & \\
\hline Climate in family &, $087^{*}$ &,- 024 &, 040 &, 067 & 1 & & & & & & & & \\
\hline Climate in school &, 061 &, $117^{* *}$ &, $085^{*}$ &, 056 &, $218^{* *}$ & 1 & & & & & & & \\
\hline Victimization &,$- 141^{*}$ &,$- 111^{* *}$ &, 027 &, $228^{* *}$ &, $103^{*}$ &, $117^{* *}$ & 1 & & & & & & \\
\hline External bullying &,$- 134^{* *}$ &, 018 &,- 019 &, $098^{*}$ &, 098 & ,099* &, $194^{* *}$ & 1 & & & & & \\
\hline Individual bullying &,$- 313^{* *}$ &, $084^{*}$ & ,039 &, 025 &,- 013 &, 043 &, $127^{*}$ &, $275^{*}$ & ** 1 & & & & \\
\hline Group bullying &, $252^{* *}$ &,- 008 &,- 078 &, $130^{* *}$ &, 044 & 077 &, $103^{*}$ &, 065 &, 042 & 1 & & & \\
\hline Friends &,$- 117^{* *}$ &,- 021 &, 005 &, 010 &, $087^{*}$ &, $105^{* *}$ &, 037 &, $169^{*}$ & 049 &,- 016 & 1 & & \\
\hline Exposure to television &, $081^{*}$ &, 017 &,- 002 &, 027 &, $116^{* *}$ &, $098^{*}$ & ,038 &, 021 & ,029 &, 055 &,- 005 & 1 & \\
\hline Exposure to violence &, 014 &, 064 &,- 053 &,$- 103^{*}$ &,$- 096^{*}$ & ,039 &,- 041 &,- 020 &,- 021 &, 048 &,- 012 &, 061 & 1 \\
\hline
\end{tabular}

** $<0,01,{ }^{*}<0,05$. 
witnessed in the preceding days. The impact of acts seen on television is noteworthy; violence of this type becomes interiorized as a daily phenomenon to which pupils begin to become accustomed. Emphasis must also be placed upon the wide-ranging repercussions of the scenes witnessed directly within the family, in the playground or just outside the school. Table 2 shows the correlations among variables.

\section{Conclusions}

Social class/municipal district is clearly a good predictor variable; this is in line with sociological theories which hold it has a determining role because lower socioeconomic classes clash with the educational system and produce bullying on individual level $(r=-.313)$. This system is usually sustained by middle-class lifestyle e. g. sacrifice, long-term gratification, non-confrontation with teachers and a rejection of violence. As various statistics show in Spain, academic failure at both early secondary school, and upper secondary years, followed by university entrance exams or vocational training and admission to or success at university is related to parents' socioeconomic class. Schools located in the city's' most deteriorated areas are under greater pressure from their surroundings; they generally have more defective buildings and worse installations (often due to the lack of support from the municipal districts).

Even private schools located in such areas have a much lower level than other private schools in areas of higher per capita income, and thus despite being private are no different in this respect from public schools. The percentage of pupils who are immigrants or belong to marginalised ethnic groups is greater and university entrance rates, once the secondary education has finished, is notably lower. It is therefore unsurprising that schools located in the lowest neighbourhoods in social (class) terms suffer more from bullying and a stronger atmosphere of victimisation.

Family atmosphere does not appear to a good independent predictive variable $(r=-.013, r=.044)$ despite the civil responsibilities which a judicial ruling has just established, since a high percentage of youths in the sample state that their family atmosphere is good. Likewise, this result is based firstly on the assumption that family influence begins to decline at this age (16, approximately). Even a hypothetical adverse economic situation is less traumatic at such an age. Neither is school atmosphere a good classificatory variable; this may seem paradoxical if we bear in mind that it is precisely schools' geographic location that determines their social class make-up, and that those schools located in deprived areas are under greater threat than others. Nevertheless, the high percentage of youths who are content with school, coupled with their belief that such an atmosphere is natural and inevitable, may provide a certain inoculation against that atmosphere. In other words, they accept that violence forms part of daily school life, this situation is probably accepted by the teachers.

Gender, as expected, significantly affects the distinction between individual $(r=.084)$ and collective bullying $(r=-.008)$. Boys' bullying is different to 
that of girls, in both quantity and typology, although the two may be equally pernicious. Physical isomorphism means that the two categories of bullying explain their inter-relations and why the mixed variety is uncommon: as females always flee from collective harassment. It also explains the difference in the practice of bullying by boys and girls. Age, however, does not discriminate between groups, probably for various reasons: the age group employed in the sample is extremely compact, in the sense that the abrupt changes caused by the onset of puberty have already begun. At these stages of school life it begins to be much less common to be attacked by an older schoolfellow, and violence continues to diminish with age. Both the frequency of television watching and exposure to violent acts appear to be important.

\section{Bibliography}

ARCHER, J.; COLE, S. (2005). «Sex differences in aggressive behaviour». Annual Review of Psychology, 53, p. 27-51.

ARnOlD, Johnson J. (1974). FAinstein, S. and CAMPBell, S. (eds.) (1996). Urban theory. Massachusetts: Blackwell.

AsKew, S. and Ross, C. (1991). Los chicos no lloran. Barcelona: Paidós.

BALDRY, A. and FARRINGTON, D. (2005). "Protective factors as moderators of risk factors in adolescence bullying». Social Psychology of Education, 8, p. 263-284.

BLOCK, J. H. et al. (1986). «The personality of children prior to divorce: a prospective study». Child Development, 57, p. 827-840.

Boulton, M. J. ( 2005). «School peer counselling for bullying services as a source of social support: a study with secondary school pupils». British Journal of Guidance and Counselling, 4, p. 485-494.

BRODY, S. (1977). Screen violence and film censorship. London: Home Office Research Study, 35.

Byrne, B. (1993). Coping with bullying at school. Dublin: The Columbia Press.

- (1994). Bullying: A Community Approach. Dublin: The Columbia Press.

- (1999). «Ireland». In: SMITH, P. K. et al. (eds.). The Nature of School Bullying. London: Routledge, p. 112-128.

CARTER, H. (1994). The study of urban geography. London: Edward.

CHANTELLE et al. (2008). "Structural and process features in three types of child care for children fronm high and low income families». Earley Childhood Research Quarterly, 23, p. 69-93.

Charlot, B. and Emin, J. C. (eds.) (1997). La violence a lécole: état des savoirs. Paris: A. Colin.

ChoI, C. Q. (2006). «Genetic Changes from Bullying». Scientific American, vol. 294, 4, p. 34.

Choldin, H. (1978). «Urban density and pathology». Annual Review of Sociology, 4, p. 91-113.

Cillessen, A. and Garandeau, C. F. ( 2006). «From indirect aggression to invisible aggression: A conceptual view on bullying and peer group manipulation. Aggression and violent behavior». A Review Journal, 6, p. 612-625.

Clark, K. (1968). Guetto negro. Mexico: Fondo de Cultura Económica.

Cuinard, M. B. (1968). Sociology of deviant behavior. New York: Holt, Rinehart \& Winston. 
Connell, R. W. (1987). Gender and power. California: Stanford University Press.

- (1995). Masculinities. Berkeley: University of California Press.

CRAiG, W. and PEPLER, D. (2003). «Identifyng and targeting risk for involvement in bullying and victimization». Canadian Journal od Psychriatry, 48, p. 577-582.

CRICK, N. et al. (2004). "Relational aggression in earley childhood». In: PUTALlaz, M. and Bierman, K. (eds.). Aggression, antisocial behaviour, and violence among girls. New York: Guilford Press, p. 71-89.

DAKE, A. J. et al. (2004). "Principals' perceptions and practices of school bullying prevention activities». Health Education \& Behavior, 3, p. 372-387.

DAVIS, J. L. et al. (2006). «Evaluation of a Bullying Prevention Program». Journal of Research in Childhood Education, vol. 21, 1, p. 91-101.

De Fleur, M. (1993). Teorías de la comunicación de masas. Barcelona: Paidós.

DEFENSOR DEL PUEBLO (2000). Violencia escolar: el maltrato entre iguales en la educación secundaria obligatoria. Madrid: Defensor del Pueblo.

Dilts-Harryman, S. (2004). "When bullies grow up. ASCA». School Counselor, 42 (2), p. 28-32.

FABRE-CORnALI, D. et al. (1999). «France». In: P. K. SMiTH et al. (ed.). The nature of school bullying. London: Routledge, p. 128-140.

FEKKES, M. et al. (2005). "Bullying: who does what, when and where? Involvement of children, teachers and parents in bullying behavior». Health Education Research: Theory \& Practice, 1, p. 81-91.

GENERALITAT DE CATALUNYA (2006). Encuesta de convivencia escolar y seguridad en Cataluña. Departamento de Educación. Barcelona: Generalitat de Catalunya.

Glover, D. et al. (1997). Anti-bullying in action. Keele: University of Keele.

GLOVER, D. et al. (2000). "Bullying in 25 secondary schools: incidence, impact and intervention». Educational Research, vol. 42, 2, p. 141-156.

GodIN, I. M. ( 2004). «Bullying, workers' health, and labour instability». Journal of Epidemiology and Community Health, 3, p. 258.

Griffin, R. S. and Gross, A. (2004). «Childhood bullying: Current empirical findings and future directions for research». Aggression and Violent Behavior, 4, p. 379-400.

GRUGEON, E. (1995). «Implicaciones del género en la cultura del patio de recreo». En Woods, P. and Hammersley, M. (eds.). Género, cultura y etnia en la escuela. Barcelona: Paidós, p. 25.

HaLl, P. (1965). Las grandes ciudades y sus problemas. Madrid: Guadarrama.

Harris, C. D. and Ullman, E. L. (1945). "The nature of cities». Annals of the American Academy of Political and Social Science, 242.

HERNÁNDEZ DE FRUTOS, T. (2000). «La violencia bullying en las relaciones de género entre escolares de Navarra». Revista Internacional de Sociología, 27, p. 73-103.

HERNÁNDEZ, T. and CASARES, E. (2002). Aportaciones teórico-prácticas para el conocimiento de actitudes violentas en el ámbito escolar. Pamplona: Gobierno de Navarra.

Hetherington, E. M. (1993). "An overview of the Virginia longitudinal study of divorce and remarriage with a focus on early adolescence». Journal of Family Psychology, 7, p. 39-56.

HoYT, H. (1939). The structure and growth of residencial neighborhoods in American cities. Washington: Federal Housing Administration.

INCE (2000). Sistema estatal de indicadores de la educación. Madrid: Ministerio de Educación, Cultura y Deporte.

Instituto NACiONAL DE CALIDAD y EVAluACión (INCE) (1997). Evaluación de la educación primaria. Madrid: Ministerio de Educación y Cultura. 
Jencks, C. and Peterson, P. (1991) (eds.). The urban underclasses. Washington: Brooking Instituttion.

Junger-TAS, J. (1993). «The Netherlands». In: P. K. SMith et al. (eds.). The nature of school bullying. London: Routledge, p. 205-224.

Kellerhals, J. and Montandon, C. (1991). «Les styles educatifs». In: Singly, F. (ed.). La famille: l'état des savoirs. Paris: La Découverte.

KELLNER, D. (1995). Media culture. London: Routledge.

KENWAY, J. and FITZCLARENCE, L. (1997). «Masculinity, violence and schooling: challenging "poisonous pedagogies"». Gender and Education, vol. 9, 1, p. 117-133.

KIM, J. E. et al. (1999). «Associations among family relationship, antisocial peers, and adolescents' externalizing behaviors: gender and family type differences». Child Development, vol. 70, 5, p. 1209-1230.

LAGERSPETZ et al. (1982). "Group aggression among school children in three schools». Scandinavian Journal of Psychology, 23, p. 45-52.

LAVIK, N. J. (1977). «Urban rural differences in rate of disorder. A comparative psychiatric population study of Norwegian adolescents». In: GRAHAM, P. J. (ed.). Epidemiological approaches in child psychiatry. London: Academic Press, p. 223-251.

Leganés, S. and Ortolá, M. (1999). Criminología. Valencia: Tirant lo Blanch.

Loeber, R. and STOUTHAMer (1987). «Prediction». In: Quay, H. C. (ed.). Handbook of juvenile delinquency. New York: Wiley, p. 325-382.

LOEBER, R. and STOUTHAMER-LOEBER, M. (1998). «Development of juvenile aggression and violence: some common misconceptions and controversies». American Psychologist, 53, p. 242-259.

LORENZ, K. (1989). Sobre la agresión: el pretendido mal. Mexico: Siglo XXI, p. 34.

LÖSEL, F. and Bliesener, T. (1999). «Germany». In: SMiTH, P. K. et al. (eds.). The nature of school bullying. London: Routledge, p. 224-250.

LOWENSTEIN, L. F. (1978). «The bullied and no-bullied child». Bulletin of the British Psychological Society, 31, p. 316-318.

MCGEE et al. (1992). «DSM-III disorders from age 11 to age 15 years». Journal of the American Academy of Child and Adolescent Psychiatry, 31, p. 50-59.

MCQuAIL, D. (1999). Introducción a la teoría de la comunicación de masas. Barcelona: Paidós.

MoffiT, T. et al. (2001). Sex differences in antisocial behaviour. Cambridge: Cambridge University Press.

MORA, J. et al. ( 2004). "The long-term effects of coping strategy: use in victims of bullying». Spanish Journal of Psychology, vol. 7, 1, p. 3-12.

OlWeus, D. (1978). Agression in the schools: Bullies and whipping boys. Washinton, D. C.: Hemisphere.

- (1979). «Stability of aggressive reaction patterns in males: A review». Psychological Bulletin, 86, p. 852-875.

- (1983). «Low school achievement and agressive behaviour in adolescent boys». In: Magnusson, D. and Allen, V. (eds.). Human development. An interactional perspective. New York: Academic Press, p. 353-365.

- (1993). Bullying at school. What we know and what we can do. Oxford: Blackwell.

- (1998). Conductas de acoso y amenazas entre escolares. Madrid: Morata, p. 25.

- (1999). «Sweden». In: P. K. SMITH et al. (eds.). The nature of school bullying. London: Routledge, p. 7-28.

Ortega, R. and Mora-Merchán, J. (1999). «Spain». In: P. K. Smith; Y. Morita; J. Junger-Tas; D. Olweus; R. Catlano and P. Slee (eds.), p. 157-174. 
Park, R. E.; Burgess E. W. and McKenzie R. D. (ed.) (1925). The city. Chicago: University of Chicago Press.

PEPLER et al. (2004). «Girls who bully: A developmental and relational perspective». In: Putallaz, M. and Bierman, K. (eds.). Aggression, antisocial behaviour, and violence among girls. New York: Guilford Press, p. 90-109.

PERrY, D. et al. (1998). «Victims of peer aggression». Developmental Psychology, vol. 24, 6, p. 807-814.

Peterson, J. S. and RaY, K. E. (2006) «Bullying among the gifted: The subjective experience». Gifted Child Quarterly, vol. 50, 3, p. 252-269.

Popenoe, D. (1996). Life without father. New York: The Free Press.

Provenzo, E. F. (2000). "Los juegos de vídeo y el surgimiento de medios interactivos para los niños». In: STEINBERG, Sh. and KinCHELOE, J. L. (eds.). Cultura infantil y multinacionales, p. 109-119.

Roland, E. and MunTHe, E. (ed.) (1989). Bullying an international perspective. London: David Fulton.

RutTer, M. (1980). Changing youth in a changing society. Cambridge: Harvard University Press.

RutTer, M. and Giller, H. (1988). Delincuencia juvenil. Barcelona: Martínez Roca.

SCHWIRIAN, K. (1993). "Models of neighborhood change». Annual Review of Sociology, 9, p. 83-102.

SHARP, S. and SMITH, P. K. (1994). Tackling bullying in your school. London: Routledge.

SHAW, C. R. and MCKAY, H. D. (1969). Juvenile delinquency and urban areas. Chicago: University of Chicago Press.

SHAW, D. et al. (1999). "A prospective study of the effects of marital status and family relations on young children's adjustement among african american and european american families». Child Development, vol. 70, 3, p. 742-755.

SiANN, G. et al. (1994). "Who gets bullied? The effect of school, gender and ethnic group». Educational Research, 36, p. 123-134.

SMITH, P. K. et al. (ed.) (1999). The nature of school bullying. London: Routledge.

Smith, P. K. and Thompson, D. (1991). Practical Approaches to Bullying. London: David Fulton Publishers.

SPENDER, D. (1983). Invisible women: schooling scandal. London: Women's Press.

STANWORTH, M. (1983). Gender and schooling. London: Hutchinson.

STEIN, A. H. and FrIEDRICH, L. K. (1975). "Impact of television on children and youth». In: Hetherington, E. M. (ed.). Review of Child Development Research, vol. 5, p. 183-256.

STEINBERG, L. (1986). «Latchkey children and susceptibility into peer presure: an ecological analysis». Developmental Psychology, 22, p. 433-439.

STEPHENSON, P. and SMiTh, D. (1992). "Why some schools don't have bullies». In: ElLIOT, M. (ed.). Bullying: a practical guide to coping for schools. Essex: Longman, p. $133-145$.

SWAIN, J. (1998). "What does bullying really mean?». Educational Research, vol. 40, 3, p. 359- 364.

WaGner, M. E. et al. (1983). «Family size effects: a review». The Journal of Genetic Psychology, 186, p. 65-78.

West, D. J. and FARRINGTON D. P. (1982). The delinquent way of live. London: Heinemann.

Whitney, I. and SMiTh, P. (1993). "A survey of the nature and extent of bullying in junior/middle and secondary schools». Educational Research, 35, p. 3-25. 
WiLSON, Julius (1993) (ed.). The ghetto underclass. Newbury Park: Sage.

- (1987). The truly disadvantaged. The inner city, the underclass, and public policy. Chicago: Chicago University Press.

WirTh, Louis (1938). «Urbanism as a way of life». American Journal of Sociology, vol. 44, 1, p. 1-24.

Zoccolillo, M. (1993). "Gender and the development of conduct disorder». Development and Psychopathology, 5, p. 65-78. 